J. Lake Sci. (湖泊科学), 2019, 31(4): 1109-1119

DOI 10. 18307/2019. 0401

(c) 2019 by Journal of Lake Sciences

\title{
洪泽湖鱼类群落结构及其资源变化
}

\author{
毛志刚 $^{1}$, 谷孝鸿 ${ }^{1 * *}$, 龚志军 ${ }^{1}$, 曾庆飞 ${ }^{1}$, 陈辉辉 ${ }^{1}$, 李红敏 ${ }^{1,2}$, 张胜宇 $^{3}$, 穆 欢 $^{3}$ \\ (1:中国科学院南京地理与湖泊研究所湖泊与环境国家重点实验室,南京 210008) \\ (2: 中国科学院大学,北京 100049) \\ (3:江苏省洪泽湖渔业管理委员会办公室,淮安 223300)
}

\begin{abstract}
摘 要: 根据 2017-2018 年在洪泽湖湖心、成子湖湾、保护区湖湾和淮河人湖口进行的鱼类资源调查,结合历年渔业捕 捞统计数据, 分析了该水域的鱼类群落结构及资源变化趋势. 调查共采获鱼类 51 种, 隶属 10 目 16 科 41 属, 其中鲤形目 种类最多, 占总数的 $62.7 \%$; 群落优势种为鳙 (Aristichthys nobilis)、、粲 (Hemiculter leucisculus)、鲫 (Carassius auratus)、刀鲚 (Coilia nasus) 等 7 种, 鱼类群落的丰富度指数、多样性指数和均匀度指数处于一般至较丰富水平. 不同类型湖区间鱼类种 类及优势种组成存在一定差异, 其中湖心、淮河人湖口的生物多样性指数整体高于成子湖湾、保护区湖湾. 与历史资料相 比, 洪泽湖鱼类的物种数量下降, 鱼类资源组成结构发生较大变化, 鱼类个体小型化趋势明显, 捕捞强度过大、水位波动 和水质污染是洪泽湖渔业资源衰退的主要因素.
\end{abstract}

关键词: 种类组成;优势种;生物多样性;渔业资源小型化;衰退因素;洪泽湖

\section{The structure of fish community and changes of fishery resources in Lake Hongze}

MAO Zhigang ${ }^{1}$, GU Xiaohong ${ }^{1 * *}$, GONG Zhijun ${ }^{1}$, ZENG Qingfei ${ }^{1}$, CHEN Huihui ${ }^{1}$, LI Hongmin ${ }^{1,2}$, ZHANG Shengyu ${ }^{3} \&$ MU Huan ${ }^{3}$

(1: State Key Laboratory of Lake Science and Environment, Nanjing Institute of Geography and Limnology, Chinese Academy of Sciences, Nanjing 210008, P.R.China)

(2: University of Chinese Academy of Sciences, Beijing 100049, P.R.China)

(3: Lake Hongze Fishery Management Commission of Jiangsu Province, Huaian 223300, P.R.China)

Abstract: Based on the historical data of fish catches and fyke nets investigations on fish assemblage from 2017 to 2018 in different lake regions of Lake Hongze, the characteristics of fish community structure and dynamic variation of fishery resources were analyzed. The results showed that only 51 species (belonging to 41 genera, 16 families and 10 orders) were collected and Cypriniformes had the largest species number, accounting for $62.7 \%$ of the total species captured. Aristichthys nobilis, Hemiculter leucisculus, Carassius auratus, Coilia nasus, etc. were the total 7 dominant species in the lake. The Margalef richness index, ShannonWiener index and Pielou evenness index were medium in the whole lake, with higher values in the estuary and central region than two bay areas. Compared with historical data, the composition of fish community and the dominant species had changed, and the miniaturized tendency of fish resources was more obvious. Overfishing, water-level fluctuation and water pollution are potential main reasons for observed shifts in the fish assemblage.

Keywords: Fish composition; dominant species; biodiversity; miniaturization of fish resources; drivers of fisheries decline; Lake Hongze

洪泽湖为中国第四大淡水湖, 湖泊面积 $1597 \mathrm{~km}^{2}$, 平均水深 $1.9 \mathrm{~m}$, 总储水量 3.04 亿 $\mathrm{m}^{3[1]}$. 洪泽湖是淮

* 国家科技支撑计划项目 (2015BAD13B01)、中国科学院南京地理与湖泊研究所 “一三五” 自主部署项目 ( NIGLAS2018GH04) 和国家自然科学基金项目 (31870449) 联合资助. 2018-09-22 收稿; 2018-11-26 收修改稿. 毛志刚( 1984 ), 男, 博士, 副研究员; E-mail: zgmao@ niglas.ac.cn.

** 通信作者; E-mail: xhgu@ niglas.ac.cn. 
河下游地区居民生活与工农业用水的重要水源地, 也是 “南水北调” 东线工程的重要输水线路和调蓄湖泊, 在防洪灌溉、交通航运以及维持生态系统平衡等方面发挥着不可替代的作用 ${ }^{[2]}$. 洪泽湖气候温和、湖面辽 阔, 有利于各类水生生物的生长繁殖, 渔业资源十分丰富 ${ }^{[3]}$. 但自 1980s 以来, 随着淮河流域经济快速发展, 面源污染物不断汇入洪泽湖, 湖泊水体质量持续下降, 水污染事件频发 ${ }^{[4]}$; 同时由于水利工程建设、过度捕 捞等多重因素的影响 ${ }^{\left[{ }^{[}\right]}$, 洪泽湖的优质渔业资源不断减少, 鱼类群落结构和生物多样性特征发生显著变化, 进而影响到洪泽湖生态系统的健康与稳定.

洪泽湖鱼类研究最早由长江水产研究所与江苏省淡水水产研究所于 1960 年进行, 其后中国科学院南 京地湖所等单位又分别组织调查组, 对洪泽湖的渔业资源进行了较为详细的综合考察 ${ }^{[3,6]}$. 这些调查内容主 要集中在鱼类种属的记录、鱼类区系的演化以及渔业资源组成特征等方面. 近年来,一些学者针对洪泽湖浮 游藻类等水生生物的分布 ${ }^{[7-8]}$ 及银鱼等经济鱼类的生物学特征 ${ }^{[9]}$ 开展了较深人的研究, 但系统的鱼类群落 调查仅林明利等 ${ }^{[10]}$ 在 2010-2011 年进行过 1 次. 目前关于洪泽湖渔业资源时空变化影响因素的探讨较少, 特别是鱼类生物多样性特征的研究还未见报道. 因此, 本研究采用定置网䈤调查分析洪泽湖鱼类群落结构 和多样性的空间分布特征, 并结合历年渔获物资料的统计整理, 探讨渔业资源的长时间尺度演变趋势及其 驱动因素, 以期为洪泽湖鱼类资源的恢复和可持续发展提供科学依据.

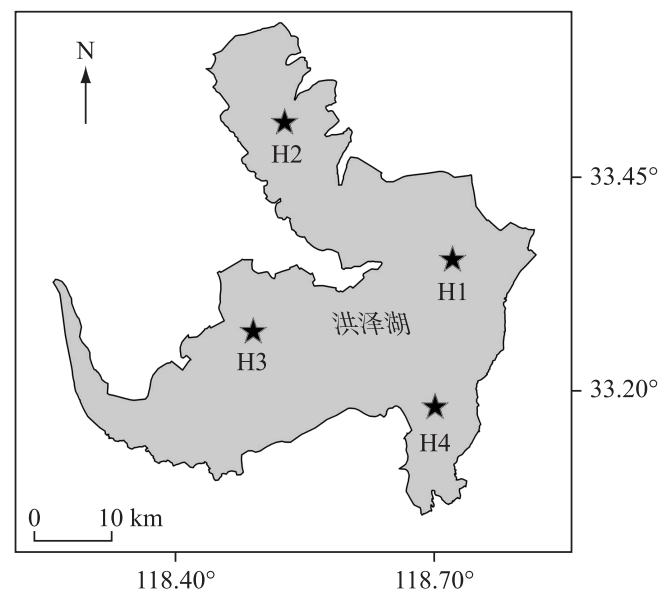

图 1 洪泽湖鱼类调查点位分布

Fig.1 Distribution of sampling stations in Lake Hongze

\section{1 材料与方法}

\section{1 研究地点}

洪泽湖水面辽阔, 且不同湖区间环境特征存在较 明显的差别, 为比较洪泽湖鱼类群落结构及其生物多 样性的空间分布特征, 将洪泽湖划分为 4 个水域: 湖 心 $(\mathrm{H} 1)$ 、成子湖湾 $(\mathrm{H} 2)$ 、保护区湖湾 $(\mathrm{H} 3)$ 和淮河人 湖口 (H4)（图 1). 其中西北部为成子湖湾, 部分沿 岸水域分布有沉水植物, 但其也受人湖污染物影响较 为严重, 夏季藻类浓度较高; 保护区湖湾周围则存在 较大面积的养殖网围; 淮河人湖口水流较快, 其占全 年人湖水量的 $90 \%$; 而湖心为大面积的敞水区域, 连 通两个湖湾与人湖口水域.

\section{2 调查方法}

2017 年 7 月洪泽湖开捕期间, 在每个样点设置 单个网篓 (拦网 $200 \mathrm{~m}$, 网目 $2 \sim 4 \mathrm{~cm}$ ) 作为调查渔具

连续监测 3 天, 并分别测量记录每天的渔获物组成; 同时, 2017-2018 年在全湖范围内收集渔民渔获物以增 加物种数. 采集的鱼类样品现场鉴定种类, 进行体长、体重等生物学测量, 并记录数量、采集地等相关数据. 采集到的部分鱼类用 $10 \%$ 甲醛溶液固定,鱼类鉴定依据倪勇等 ${ }^{[11]}$ 进行,并参考鱼类专家的鉴定意见.

各湖区总氮 $(\mathrm{TN})$ 、总磷 $(\mathrm{TP})$ 、透明度、叶绿素 $\mathrm{a}(\mathrm{Chl} . \mathrm{a})$ 等水质指标及水生植物分布特征的测定与鱼类 采样同步进行,具体结果见表 1 .

表 1 洪泽湖不同湖区环境特征比较

Tab.1 Environment characteristics in different lake regions of Lake Hongze

\begin{tabular}{|c|c|c|c|c|c|c|c|}
\hline 湖区 & $\begin{array}{c}\text { 水深/ } \\
\mathrm{m}\end{array}$ & $\begin{array}{c}\text { 透明度/ } \\
\text { m }\end{array}$ & $\begin{array}{c}\mathrm{TN} / \\
(\mathrm{mg} / \mathrm{L})\end{array}$ & $\begin{array}{c}\mathrm{TP} / \\
(\mu \mathrm{g} / \mathrm{L})\end{array}$ & $\begin{array}{c}\text { Chl.a/ } \\
(\mu \mathrm{g} / \mathrm{L})\end{array}$ & $\begin{array}{c}\text { 水草盖度/ } \\
\%\end{array}$ & 其他特征 \\
\hline 湖心 H1 & 2.4 & 0.35 & 1.88 & 73.5 & 30.9 & 5 & 连通两个湖湾与人湖口 \\
\hline 成子湖湾 H2 & 2.0 & 0.42 & 1.39 & 80.3 & 47.4 & 27 & 人湖河流污染物较多 \\
\hline 保护区湖湾 H3 & 2.0 & 0.46 & 1.47 & 56.6 & 42.4 & 12 & 存在大面积养殖网围 \\
\hline 淮河入湖口 H4 & 5.7 & 0.26 & 2.59 & 136.2 & 3.0 & 2 & 水流较快, 大量悬浮颗粒物 \\
\hline
\end{tabular}




\section{3 数据分析}

洪泽湖 2000-2016 年的渔业捕捞产量数据由洪泽湖渔业管理委员会办公室提供, 渔获物种类及产量均 为各大队统计数据, 渔具主要为网箱、刺网、拖网等.

采用 Pinkas 等 ${ }^{[12]}$ 的相对重要性指数 $(I R I)$ 来研究鱼类群落优势种的成分:

$$
I R I=(N \%+W \%) F \%
$$

式中, $N \%$ 为某一种鱼类的尾数占总尾数的百分比, $W \%$ 为某一种鱼类的质量占总质量的百分比, $F \%$ 为某一 种鱼类出现的站数占调查总站数的百分比. 本文选取 IRI 值大于 500 的物种为优势种.

鱼类群落多样性的分析采用 Margalef 物种丰富度指数 $(D)$ 、Shannon-Wiener 多样性指数 $\left(H^{\prime}\right)$ 和 Pielou 均匀度指数 $\left(J^{\prime}\right)^{[13]}$, 公式分别为:

$$
\begin{gathered}
D=(S-1) / N \\
H^{\prime}=-\sum_{i=1}^{S} P_{i} \cdot \ln P_{i} \\
J^{\prime}=H^{\prime} / \ln S
\end{gathered}
$$

式中, $S$ 为种类数, $N$ 为总尾数, $P_{i}$ 为第 $i$ 种鱼类所占的比例.

生物多样性指数分级评价参照环保部发布的国家环境保护标准 (HJ 442-2008), 根据 $H^{\prime}$ 指数范围将生 物多样性水平划分为极贫乏、贫乏、一般、较丰富和丰富 5 个级别.

各湖区间鱼类群落的种类、优势种与多样性指数分析以每个点位连续 3 天的整体监测数据为依据, 而 各湖区间生物多样性指标的差异性分析则以每天的监测数据为依据. 全部数据的统计分析采用 SPSS 19.0 软件完成.

\section{2 结果与分析}

\section{1 鱼类种类与生态类型}

本次调查在洪泽湖水域共采集到鱼类 51 种, 隶属 10 目 16 科 41 属, 其中题吻鲟 (Polyodon spathula) 和 黄尾鲖 (Xenocypris davidi) 为新记录种 (表 2). 鲤形目 (32 种) 种类最多, 占调查物种总数的 $62.7 \%$; 其次是鲈 形目 (6 种), 其他各目 $1 \sim 3$ 种. 在科的水平上, 鲤科 (31 种) 种类最多, 银鱼科 3 种, 魭科、塘鳢科、虾虎鱼科 各 2 种, 其他 11 科各 1 种. 洪泽湖湖心、成子湖湾、保护区湖湾和淮河人湖口分别采集到鱼类 $32 、 35 、 29$ 和 36 种,且各湖区均以鲤形目鱼类为主,分别占总数的 $71.4 \% \sim 79.3 \%$,其他目的种类数较少.

洪泽湖鱼类按其栖息环境和洄游方式可分为 3 种生态类型 (表 2 ). 海淡水洄游性鱼类:鳗鲟 (Anguilla japonica)、刀鲚 (Coilia nasus)、大银鱼 (Protosalanx hyalocranius)、乔氏新银鱼 (Neosalanx jordani)、陈氏短吻 银鱼 (Salangichthys jordani) 和间下鱵 (Hyporhamphus intermedius) 6 种, 占洪泽湖鱼类物种总数的 $11.8 \%$; 其中 除鳗鲟外, 刀鲚、大银鱼等 5 种鱼类因长期陆封, 逐渐适应了湖内的生态条件, 并能在湖中自然繁殖, 成为次 生的定居性种类. 江湖半洄游性鱼类: 鲢 (Hypophthalmichthys molitrix)、鳙(Aristichthys nobilis)、赤眼䲡( Squaliobarbus curriculus) 等 7 种鱼类, 占总数的 $13.7 \%$, 其中四大家鱼主要依靠人工增殖放流维持. 湖泊定居性鱼 类共有 38 种鱼类,占总数的 $74.5 \%$, 这些鱼类为洪泽湖鱼类资源的主体, 且均能在湖区水域内完成繁殖 生长.

参照鱼类食性文献资料 ${ }^{[14]}$ 可将洪泽湖鱼类划分为杂食性、肉食性、鱼食性、草食性、浮游动物食性、碎屑 食性等营养生态类型 (表 2). 鲤 (Cyprinus carpio)、鲫 (Carassius auratus) 等鱼类对动植物食物都能摄食, 为典 型的杂食性鱼类, 其种类数量最多, 占总数的 $29.4 \%$; 青鱼 (Myloparyngodon piceu)、花鳃 (Hemibarbus maculatus) 等以底栖生物为食的温和肉食性鱼类, 以及翅嘴鲌 (Culter alburnus)、䱛(Elopichthys bambusa) 等 凶猛性的鱼食性鱼类次之, 分别占 $23.5 \%$ 和 $17.6 \%$; 浮游动物食性鱼类、草食性鱼类和碎屑食性鱼类则分别 占 $13.7 \% 、 11.8 \%$ 和 $3.9 \%$.

\section{2 鱼类优势种组成}

按照 IRI 值的大小对所捕获鱼类进行排序, 全湖及各调查湖区排在前 10 位的种类及其资源指数均列于 表 3. 全湖区域内的优势种鱼类依次为鳙、粲 (Hemiculter leucisculus)、鲫、刀鲚、红鯺原鲌 (Cultrichthys erythrop- 


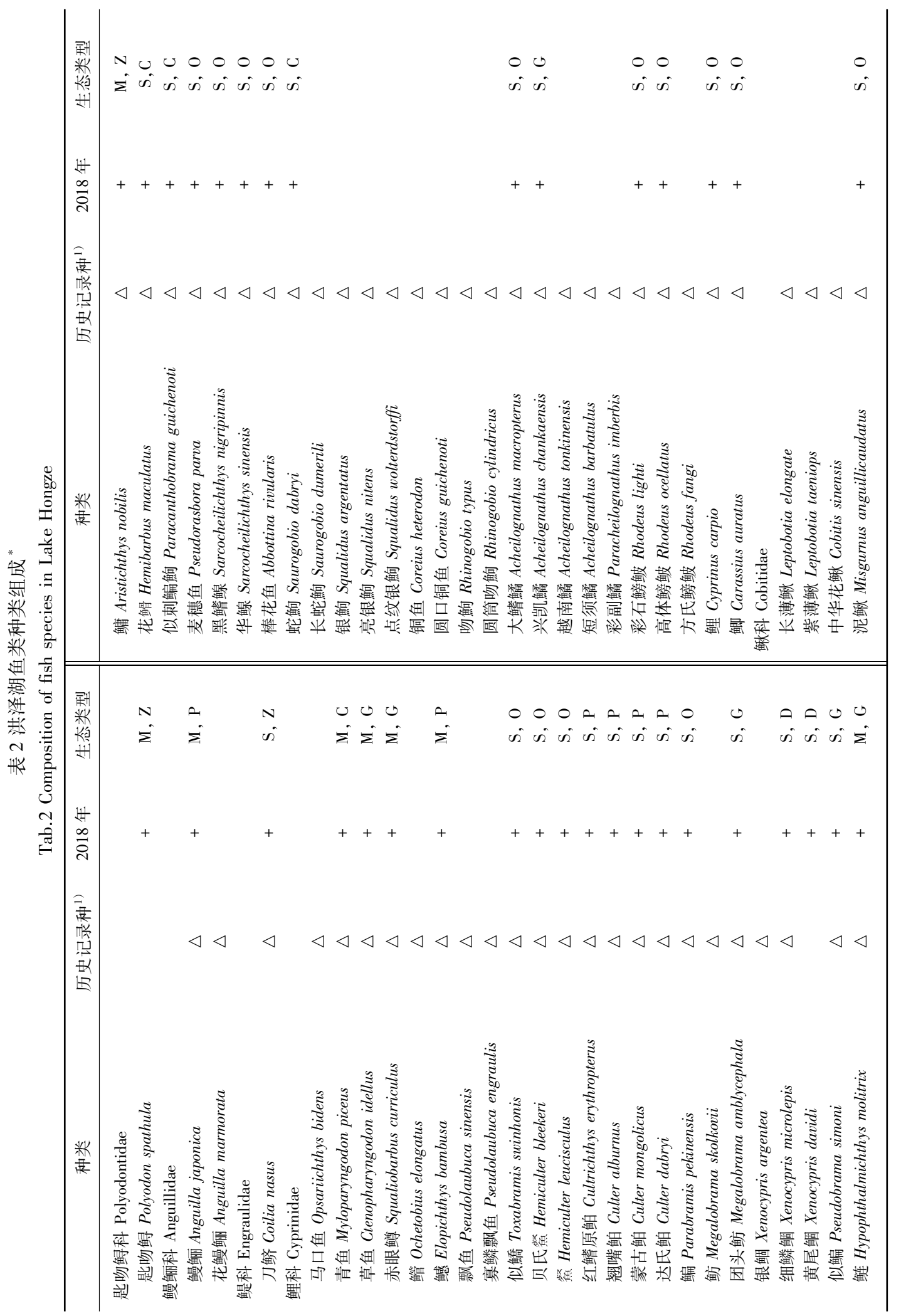




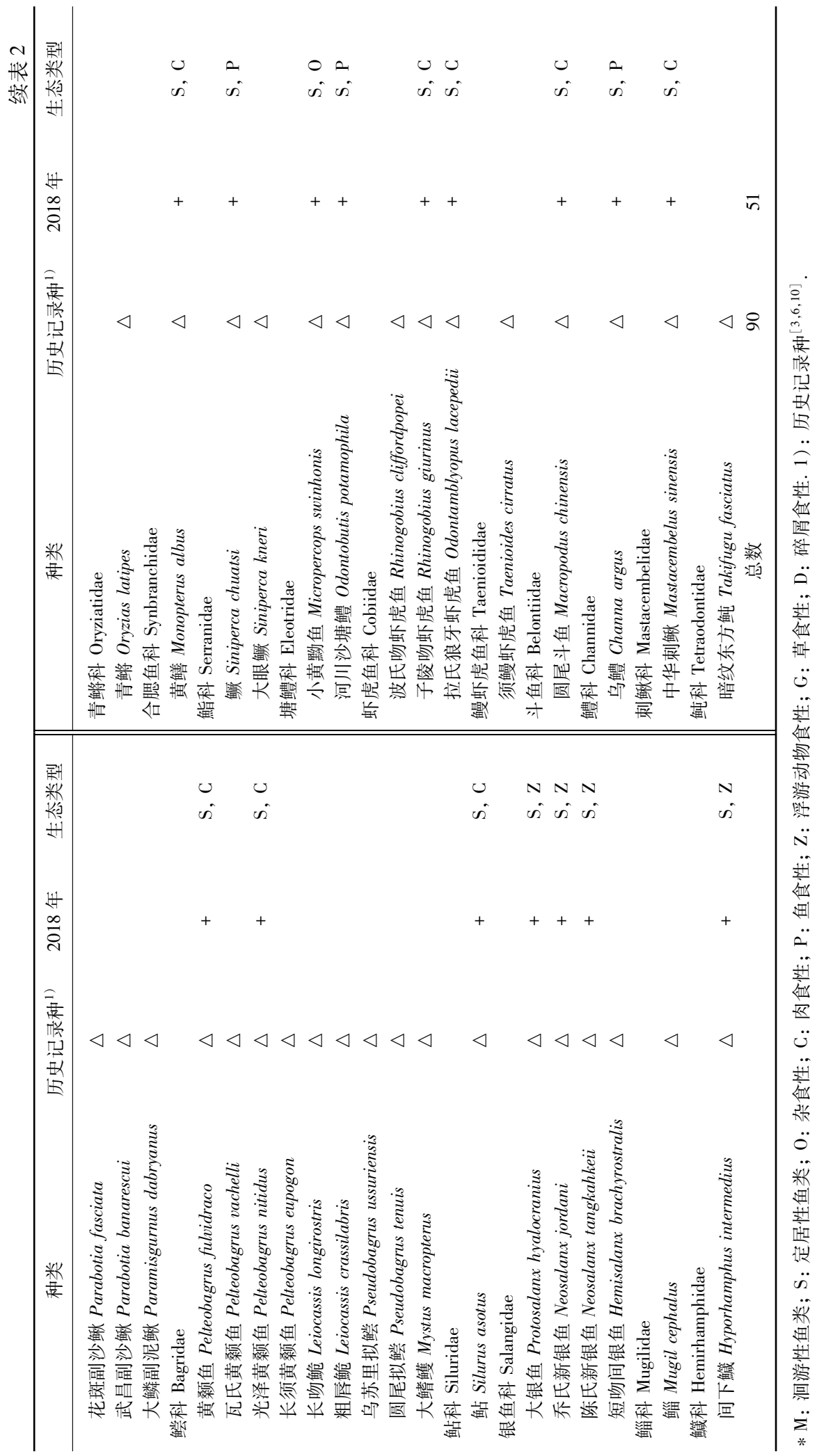


terus)、黄颡鱼 (Pelteobagrus fulvidraco) 和鲢共 7 种 (IRI 值大于 500), 而这几种鱼在不同水域的优势度则存在 一定差别, 其中鳙在湖心和成子湖湾优势程度显著, 粲在保护区湖湾分布优势明显, 而鲫在淮河人湖口区域 占绝对优势. 洪泽湖鱼类优势种中, 鳙的 IRI 值最高, 其质量百分比占渔获物总量的 $41.1 \%$, 但其数量百分比 仅占 $2.0 \%$. 除鲢、鳙外,其他优势种均为中小型鱼类,这些鱼类的质量百分比总和为 $43.4 \%$ (表 3 ).

表 3 洪泽湖不同湖区的鱼类优势种组成 ${ }^{*}$

Tab.3 Composition of dominant fish species in different lake regions of Lake Hongze

\begin{tabular}{|c|c|c|c|c|c|c|c|c|c|c|c|c|c|c|c|}
\hline \multirow{2}{*}{ 种类 } & \multicolumn{3}{|c|}{ 全湖 } & \multicolumn{3}{|c|}{ 湖心 (H1) } & \multicolumn{3}{|c|}{ 成子湖湾 ( H2) } & \multicolumn{3}{|c|}{ 保护区湖湾( H3) } & \multicolumn{3}{|c|}{ 淮河人湖口（H4） } \\
\hline & $N \%$ & $W \%$ & IRI & $N \%$ & $W \%$ & IRI & $N \%$ & $W \%$ & $I R I$ & $N \%$ & $W \%$ & IRI & $N \%$ & $W \%$ & $I R I$ \\
\hline 鳙 & 2.0 & 41.1 & 4315.7 & 1.8 & 42.0 & 4373.3 & 3.2 & 53.9 & 5707.7 & 2.2 & 43.9 & 4616.9 & 1.0 & 24.7 & 2564.9 \\
\hline 粲 & 27.3 & 7.3 & 3462.2 & 24.6 & 7.6 & 3224.4 & 21.1 & 4.4 & 2552.1 & 42.5 & 10.6 & 5311.5 & 21.0 & 6.6 & 2760.9 \\
\hline 鲫 & 16.7 & 17.7 & 3447.2 & 13.9 & 15.6 & 2949.4 & 17.1 & 14.5 & 3159.8 & 17.8 & 18.6 & 3641.3 & 18.2 & 22.2 & 4038.1 \\
\hline 刀鲚 & 25.6 & 4.4 & 3002.8 & 29.8 & 5.6 & 3533.8 & 36.9 & 4.7 & 4159.8 & 17.4 & 3.0 & 2036.5 & 18.6 & 4.2 & 2281.3 \\
\hline 红鯺原鲌 & 11.0 & 9.7 & 2063.8 & 9.4 & 8.6 & 1802.9 & 8.8 & 5.9 & 1466.9 & 10.2 & 9.0 & 1924 & 15.5 & 15.1 & 3061.2 \\
\hline 黄颡鱼 & 8.5 & 4.3 & 1278.5 & 8.3 & 4.4 & 1270.7 & 4.8 & 1.6 & 643.7 & 3.1 & 1.4 & 449.8 & 17.7 & 9.8 & 2749.8 \\
\hline 鲢 & 0.3 & 4.9 & 523.0 & 0.3 & 5.7 & 607.6 & 0.4 & 4.8 & 522.6 & 0.4 & 5.7 & 618.5 & 0.1 & 3.3 & 343.4 \\
\hline 草鱼 & 0.1 & 2.8 & 277.3 & - & - & - & 0.2 & 4.5 & 474.2 & - & - & - & 0.1 & 2.8 & 288.0 \\
\hline 光泽黄颡鱼 & 2.1 & 0.5 & 265.1 & 2.3 & 0.7 & 290.4 & - & - & - & - & - & - & 4.1 & 1.1 & 521.2 \\
\hline 麦穗鱼 & 1.9 & 0.1 & 200.8 & 3.6 & 0.3 & 387.3 & 1.9 & 0.1 & 197.7 & 1.6 & 0.1 & 174.6 & - & - & - \\
\hline 高体鳑鲏 & - & - & - & 2.9 & 0.3 & 325.9 & - & - & - & - & - & - & - & - & - \\
\hline 乌鳢 & - & - & - & - & - & - & 0.8 & 1.4 & 213.9 & - & - & - & - & - & - \\
\hline 团头鲂 & - & - & - & - & - & - & - & - & - & 0.6 & 1.3 & 190.6 & - & - & - \\
\hline 鲤 & - & - & - & - & - & - & - & - & - & 0.1 & 1.4 & 155.5 & - & - & - \\
\hline 翅嘴鲌 & - & - & - & - & - & - & - & - & - & - & - & - & 0.2 & 3.7 & 388.9 \\
\hline
\end{tabular}

* 表中仅列出了各湖区 IRI 值在前 10 位的鱼类种类 ( 优势种, $I R I>500)$.

\section{3 生物多样性指数}

洪泽湖鱼类群落的多样性指数分级评价结果显示, 其生物多样性总体处于一般至较丰富的程度 (表 4), 其中不同湖区间 $D$ 的变动幅度较大, 处于 $3.32 \sim 4.13$ 之间, 平均值为 3.72. $H^{\prime}$ 和 $J^{\prime}$ 均用生物量和个体数量两 种方法计算, $H^{\prime}{ }_{\mathrm{N}} 、 H^{\prime}{ }_{\mathrm{W}}$ 的变动范围分别为 $1.75 \sim 2.00$ 和 $1.72 \sim 2.22, J^{\prime}{ }_{\mathrm{N}} 、 J^{\prime}{ }_{\mathrm{W}}$ 的变动范围分别为 $0.31 \sim 0.58$ 和 $0.32 \sim 0.62$, 其中基于个体数量的多样性指标 $H^{\prime}{ }_{\mathrm{N}} 、 J^{\prime}{ }_{\mathrm{N}}$ 略低于基于生物量的多样性指标 $H^{\prime}{ }_{\mathrm{W}} 、 J^{\prime}{ }_{\mathrm{W}}$.

表 4 洪泽湖不同湖区的鱼类生物多样性指数

Tab.4 Diversity indexes of fish community in different lake regions of Lake Hongze

\begin{tabular}{|c|c|c|c|c|c|}
\hline \multirow{2}{*}{ 区域 } & \multirow{2}{*}{$\frac{\text { Margalef 指数 }}{D}$} & \multicolumn{2}{|c|}{ Shannon-Wiener 指数 } & \multicolumn{2}{|c|}{ Pielou 均匀度 } \\
\hline & & $H_{\mathrm{N}}^{\prime}$ & $H^{\prime}{ }_{\mathrm{W}}$ & $J^{\prime}{ }_{\mathrm{N}}$ & $J_{W}^{\prime}$ \\
\hline H1 & 3.47 & 2.00 & 2.02 & 0.58 & 0.58 \\
\hline $\mathrm{H} 2$ & 4.13 & 1.88 & 1.72 & 0.53 & 0.48 \\
\hline H3 & 3.32 & 1.75 & 1.84 & 0.31 & 0.32 \\
\hline H4 & 3.95 & 1.96 & 2.22 & 0.55 & 0.62 \\
\hline 全湖 & 3.72 & 1.90 & 1.95 & 0.49 & 0.50 \\
\hline
\end{tabular}

各湖区鱼类多样性的判别指数 $D 、 H^{\prime}$ 和 $J^{\prime}$, 整体表现为湖心 ( H1)、淮河人湖口 ( H4) 高于成子湖湾 ( H2)、保护区湖湾 (H3). 此外, 对 4 个湖区各项鱼类生物多样性指标进行单因子方差分析, 其中仅丰富度指 数 $D$ 及均匀度指数 $J^{\prime}{ }_{\mathrm{W}}$ 间呈显著性差异 $(P<0.05)$.

\section{4 渔业资源变化趋势}

洪泽湖近年来的渔获物历史统计数据如图 2 所示,2000-2016 年 17 年间,洪泽湖鱼类捕捞产量的发展 
趋势大致可分为增长和波动 2 个阶段. 增长阶段: 2000-2008 年捕捞产量呈现持续增长趋势, 从初始的 3060 $\mathrm{t}$ 逐步增加至 $14380 \mathrm{t}$, 平均每年增长 $1258 \mathrm{t}$; 波动阶段: 2009-2016 年期间, 捕捞产量开始呈现波动特征, 其 中 2014 年的捕捞量仅为 $10267 \mathrm{t}$, 而 2015 年则迅速增长 1.1 倍, 达到 $21191 \mathrm{t}$.

洪泽湖不同年份的捕捞渔业资源结构如表 5 所示 (不含虾蟹), 其中 1949 年鲤、鲫和四大家鱼等大中型 鱼类的比例占 $59.1 \%$, 优质鱼类资源较丰富, 渔业结构相对合理; 但 1982 年大中型鱼类的比重下降至 $34.9 \%$, 而 2000- 2016 年期间,其比重也仅维持在 33.1\% 44.0\%. 与之相对, 图 2 和表 5 均显示洪泽湖渔获 物组成中, 小型浮游动物食性鱼类银鱼和刀鲚的产量均有较大幅度上升, 尤其刀鲚所占比重从 1949 年的 $1.1 \%$ 逐步增至目前 (2009-2016 年) 的 45.3\%, 成为洪泽湖鱼类群落中的绝对优势种群. 以刀魰为代表的这 种状况典型地反映了洪泽湖鱼类优势种“单一化”和“小型化”的资源衰退趋势.

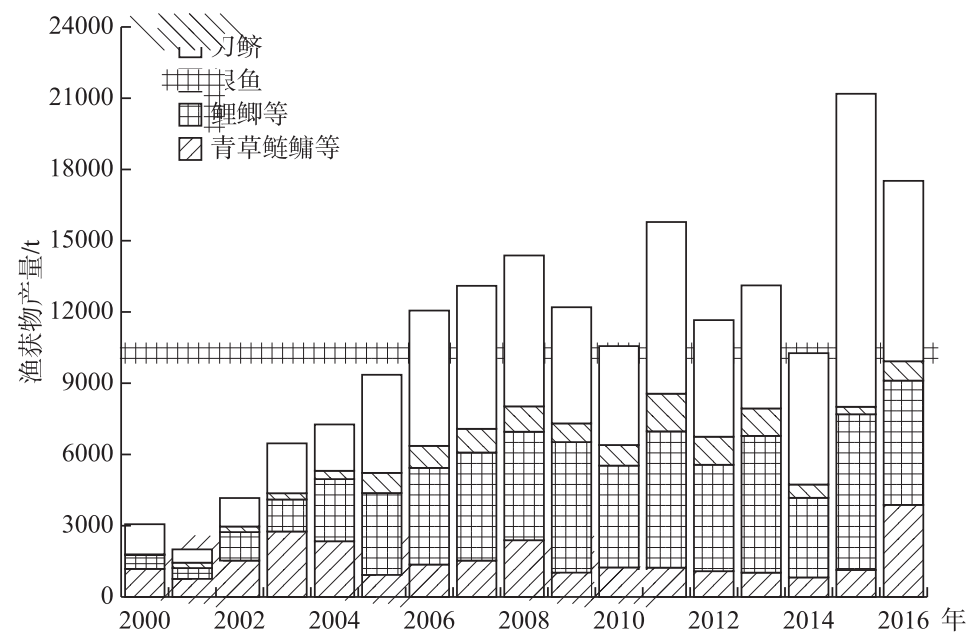

图 2 2000-2016 年洪泽湖渔业捕捞产量变动趋势

Fig.2 Changes of fish catches in Lake Hongze from 2000 to 2016

\section{3 讨论}

\section{1 鱼类种类组成历史变化}

洪泽湖鱼类种类与区系组成的研究始于 1960 s, 长江水产研究所与江苏省淡水水产研究 所等单位在 1960、1981 年对洪泽湖鱼类资源开 展了两次调查, 分别记录鱼类 15 科 55 种和 16 科 84 种 $^{[3]}$; 之后, 朱松泉等 ${ }^{[6]}$ 在 $1989-1990$ 年的调 查中采集到鱼类 67 种. $2010-2011$ 年,林明利 等 ${ }^{[10]}$ 进行的洪泽湖鱼类调查中采集到鱼类 63 种, 并根据以往文献记载, 整理记录出洪泽湖鱼 类种类共有 88 种.

与前几次调查结果相比, 洪泽湖鱼类的物种 数量减少,鱼类种类组成发生较为明显的变化. 首先,一些海淡水洄游性鱼类和江湖洄游性鱼类 减少或消失,如鲻(Mugil cephalus) 等在本次调查 中未采集到, 而鳗鲡、鳡的数量也极少, 且可能为增殖放流或养殖逃逸的种群. 洪泽湖近几十年来大量兴建 闸坝, 其作为洄游性鱼类繁殖场所和洄游通道的功能弱化, 洄游性鱼类几近消失. 其次, 洪泽湖中马口鱼
表 5 洪泽湖不同年代的渔获物组成比例

Tab.5 Composition of fish catches in different years in Lake Hongze

\begin{tabular}{|c|c|c|c|c|}
\hline & 1949 年 & 1982 年 & $\begin{array}{l}2000- \\
2008 \text { 年 }\end{array}$ & $\begin{array}{l}2009- \\
2016 \text { 年 }\end{array}$ \\
\hline 渔获物总产量/t & / & 11570 & 7981 & 14038 \\
\hline 均产量/ $\left(\mathrm{kg} / \mathrm{hm}^{2}\right)$ & / & 72.4 & 50.0 & 87.9 \\
\hline \multicolumn{5}{|l|}{ 渔获物组成/\% } \\
\hline 四大家鱼等 & 16.1 & 5.6 & 26.4 & 11.0 \\
\hline 鲤、鲫 & 43.0 & 29.3 & 17.6 & 22.1 \\
\hline 银鱼 & 0.5 & 4.2 & 6.5 & 6.9 \\
\hline 刀鲚 & 1.1 & 31.3 & 37.7 & 45.3 \\
\hline 其他 & 39.3 & 29.6 & 11.8 & 14.7 \\
\hline 增殖放流鱼类 & 16.1 & 5.6 & 26.4 & 11.0 \\
\hline 自繁鱼类 & 83.9 & 94.4 & 73.6 & 89.0 \\
\hline
\end{tabular}


(Opsariichthys bidens)、银鮈 (Squalidus argentatus)、中华花鱾 (Cobitis sinensis) 等喜清澈溪流环境的鱼类在本 次调查中未采集到, 一方面洪泽湖周边流域范围内的河道溪流, 水质逐年恶化, 生态环境以难以适合这些鱼 类种类的生存; 另一方面, 洪泽湖的水利设施建设与调水工程, 使其呈现出湖区水位反季节波动的趋势, 不 利于河道溪流与湖泊的交互连通 ${ }^{[15]}$. 另外, 围湖造田、大面积网围养殖以及工农业污染, 造成湖岸水域内的 水生植被大量破坏 ${ }^{[16]}$, 沿岸带产卵的定居性鱼类减少; 而渔业资源的过度捕捞, 进一步导致部分具有地域性 经济价值的鱼类,如花鳃(Hemibarbus maculates) 和似刺鳊鮈 (Paracanthobrama guichenoti) 等几乎难以捕获.

洪泽湖鱼类的种类组成近年来还出现了一些新的危机, 鱼类外来种的人侵可能会对鱼类群落的结构和 功能产生负面的生态效应. 人侵种可以改变群落或生态系统基本的生态学特征, 如群落中的优势种、食物网 的营养循环以及导致区域性的生物多样性减少等 ${ }^{[17]}$. 本次调查中新记录了匙吻鲟这种鱼类, 但其出现率 ( $8.3 \%)$ 与个体数量 ( 2 尾) 均较低, 推断可能来自于上游养殖池塘的逃逸. 匙吻鲟原为美国密西西比河流域 物种, 但近年来由于消费需求的增长, 匙吻鲟的人工养殖在国内兴起. 此外, 太湖等湖泊近年来也陆续发现 一些外来物种 ${ }^{[18]}$, 例如露斯塔野鲮 (Labeo rohita) 和胡鲇 (Clarias batrachus) 等. 如果这些 “新种” 入湖后, 能 够在湖区内繁殖、扩散并逐步形成稳定的种群, 往往会给土著种带来严重影响. 因此, 在全球范围内均受到 人侵物种影响的背景下, 国内也需要密切关注洪泽湖等重要湖泊可能面临的生物人侵的潜在危害.

\section{2 鱼类小型化趋势与生物多样性}

根据历史渔业资料分析, 1949 年鲤、鲫和四大家鱼等大中型鱼类的比例占 $59.1 \%$, 但自 1982 年起, 大中 型鱼类的比重逐步下降至 33.1\% 44.0\% (表 5). 与之相对, 刀鲚和银鱼等小型浮游动物食性鱼类的比重不 断增加, 其中刀鲚所占比重增至目前的 $45.3 \%$, 在数量及生物量上均占绝对优势. 由此可见, 洪泽湖鱼类主 要优势种由大中型鱼类逐渐转变成小型鱼类,渔业资源整体质量呈下滑趋势.

与此同时, 本次研究利用网籍开展的鱼类群落现状调查结果显示, 洪泽湖全湖区域内的优势种依次为 鳙、粲、鲫、刀鲚等 7 种鱼类,其中鳙的质量百分比占渔获物总量的 $41.1 \%$, 但其数量百分比仅占 $2.0 \%$; 刀鲚 的质量百分比仅占 $4.4 \%$, 但其数量百分比达到 $25.6 \%$ (表 3). 本次调查采用网籍来评估鱼类资源, 渔获物以 大中型鱼类及体长达到一定规格的刀魰为主; 而洪泽湖渔管办提供的历史统计数据则包括网䈤、刺网、拖 网、兒网等, 其中拖网、兒网等渔具中的渔获物, 以体长小于 $10 \mathrm{~cm}$ 的刀鲚、银鱼等小型鱼类为主, 但这些渔具 又由于人为干扰和拖网速度较慢等因素, 造成部分活动能力较强的大中型鱼类逃逸. 因此, 本次网䈤渔获物 统计的刀鲚比重, 相对低于洪泽湖渔管办的统计数据.

相应的, 本次调查的洪泽湖鱼类群落的多样性指数 $H^{\prime}{ }^{\prime}$ 在各湖区表现为一般至较丰富的水平 $(1.72 \sim$ 2.22 ), 处于 Magurran ${ }^{[19]}$ 提出的多样性指数的一般范围之间 (1.5 3.5). 目前国内湖泊普遍出现低营养层次 的小型中上层鱼类资源逐渐增加, 而优质高营养层次鱼类资源相继衰退的趋势 ${ }^{[20]}$. 与其他一些出现鱼类小 型化趋势的大型湖泊相比, 洪泽湖鱼类群落多样性指数 $H^{\prime}{ }_{\mathrm{W}}(1.95)$ 高于太湖 $(0.46)^{[18]}$ 、呼伦湖 $(0.71)^{[21]}$ 和 博斯腾湖 $(1.14)^{[22]}$. 此外, 本研究中鱼类群落 $H^{\prime}{ }_{\mathrm{N}}$ 与 $H^{\prime}{ }_{\mathrm{W}}$ 基本一致, 表明洪泽湖的大中型鱼类与小个体鱼类 比例相当 ${ }^{[23]}$, 而这与太湖等其他一些湖泊中的研究结论相反 ${ }^{[18,21]}$, 这也间接验证了洪泽湖鱼类生物多样性 指数相对较高的调查结果.

洪泽湖鱼类群落生物多样性相对较高可能主要由两个因素导致: 一方面, 洪泽湖刀魰等小型鱼类的比 重确实低于太湖 $(88 \%)^{[18]}$ 、呼伦湖 ( $\left.83 \%\right)^{[21]}$ 和博斯腾湖 $(65 \%)^{[22]}$, 即使基于洪泽湖渔管办的统计数据 $(52 \%)$; 另一方面, 这几个湖泊调查采样的渔具也存在网目或类型上的差别, 使得捕获的鱼类种群个体特征 产生人为差异. 例如, 太湖鱼类生物多样性的调查采用的是拖网, 由于较小的网目与围捕速度, 其渔获物中 游速较慢的小型鱼类比重更高 ${ }^{[18]}$. 因此, 采用不同捕捞渔具会对渔业资源的统计存在较大影响, 利用单种 渔具对湖泊鱼类群落进行评估时可能会造成一定误差 ${ }^{[24]}$, 今后的研究工作中应制定和采取统一的湖泊鱼类 标准调查方法,并通过统计学等分析手段整合不同渔具的调查数据 ${ }^{[25]}$.

\section{3 鱼类群落及渔业资源时间与空间变化的影响因素}

上文关于鱼类资源变动的分析结果显示, 洪泽湖鱼类群落与资源结构在长时间尺度上呈现出优势种单 一化和小型化的衰退趋势, 其在很大程度上是人为因素和环境因素共同作用的结果. (1) 捕捞是渔业资源衰 退和生物多样性降低的主要影响因素: 持续的捕捞强度下, 个体较大、生命周期较长的高营养级捕食者逐步 
减少,并导致渔获物的组成向个体较小、营养层次较低、经济价值不高的种类转变 ${ }^{[26]}$. 洪泽湖生产渔具包括 拖网、网筙、覍网、刺网、虾网等,各类渔具网目不一,对鱼类规格几乎没有选择性,基本将大小鱼类全部捕获. 在这种高捕捞强度下, 刀魰等小型鱼类较之大型鱼类具有更强的补偿调节能力, 而这种影响又通过一些生 态学过程放大, 例如大型鱼食性鱼类种群的衰退降低了其对小型鱼类种群的捕食与调控作用, 最终对群落 结构进一步产生影响. (2) 洪泽湖逐年升高的富营养化水平也与刀鲚产量及其整体比重的增加密切相关: 水 体氮磷浓度增加通常会造成浮游藻类的快速增长以及湖泊初级生产力的提高, 进而浮游动物数量也得到一 定程度的增长 ${ }^{[27]}$. 刀魰为典型的浮游动物食性鱼类, 洪泽湖富营养化进程 ( TN 、Chl. a 年均浓度从 2000 年的 $1.58 \mathrm{mg} / \mathrm{L} 、 4.3 \mu \mathrm{g} / \mathrm{L}$ 分别增至 2017 年的 $2.29 \mathrm{mg} / \mathrm{L} 、 13.9 \mu \mathrm{g} / \mathrm{L}$ ) 为刀鲚提供了充足的食物饵料, 也间接促进 了其种群的快速扩张. (3) 水文条件的改变也能引起鱼类资源的变动: 水位升高或人湖径流补水量减少等均 可能对鱼类种群数量及分布产生重要影响 ${ }^{[28]}$. 近年来, 洪泽湖作为 “南水北调” 东线工程的调蓄湖泊, 以及 自身防洪灌溉、交通航运的需求, 水利部门加强了对其水位的调控力度, 洪泽湖水位也呈现出反季节及年际 波动的特征. 一方面,水位下降会导致湖体水域面积萎缩、蓄水量迅速降低,鱼类的生存空间与饵料生物减 少; 另一方面水位反季节升高容易影响水生植被的萌发生长, 而洪泽湖水生植被的分布面积也在逐年减 少 ${ }^{[16]}$, 以水草为附着物的粘性卵鱼类的繁殖受到显著影响. 因此, 洪泽湖的渔业捕捞产量近年来也随水文 条件的变化而显示出较强的波动性(图 2).

洪泽湖鱼类群落结构的空间分布差异一定程度上反映出其与湖泊环境特征相适应的特点. (1) 鱼类生 物多样性的空间差异与不同湖区间的环境异质性密切相关: 例如湖心和人湖口水域的鱼类多样性指数 $D 、 H^{\prime}$ 和 $J^{\prime}$ 整体高于 2 个湖湾, 其中淮河人湖口直接连通了淮河与长江, 是鱼类洄游、迁移和繁殖的重要通道, 而 湖心区则处于湖湾和人湖口交汇的水域, 因此这些区域的鱼类种类数量或生物多样性指数相对较高. (2) 鱼 类优势种组成的差别也与各湖区的覀料生物分布特征相一致 (表 1): 例如成子湖湾鳙的 $I R I$ 值明显高于其 他鱼类, 而成子湖湾的 Chl. a 浓度也为各湖区最高, 其浮游藻类为鳙提供了丰富的生物旿料; 同时, 成子湖湾 沿岸分布大量的沉水植物,因此其草鱼的 IRI 值也相对高于其他湖区.

综上,洪泽湖鱼类小型化趋势加剧, 很大程度上应该是人为捕捞、水利调控和自然环境因素共同作用的 结果. 针对洪泽湖渔业目前面临的问题, 如何控制渔业资源衰退, 并在考虑保护生物多样性与湖泊生态环境 的前提下进行鱼类资源结构优化调整, 是目前迫切需要研究的内容. 洪泽湖渔业及环境保护等管理部门后 期可在以下 4 个方面开展相关工作: (1) 鱼类多样性保护: 积极构建洪泽湖流域水生生物多样性观测网络与 评估体系,严格管控采砂等破坏珍稀、濒危、特有物种栖息地的人类活动, 形成完善的水生生物多样性保护 政策与法律法规; (2) 捕捞强度控制: 建议将洪泽湖鱼类开捕日期从 7 月 1 日推迟至 9 月 1 日, 延长亲鱼繁 殖保护期的同时, 可以较大幅度提高鱼类捕捞规格; 严格限制渔具网目规格, 逐步淘汰落后渔具, 分阶段安 置和减少专业渔民数量, 减轻洪泽湖整体渔业捕捞强度; (3) 增殖放流: 调整完善洪泽湖现有鱼类增殖放流 规划与模式, 规范放流规程与相关保护性措施, 推进系统化的鱼类增殖放流管理体系构建; 开展鱼类关键洄 游通道与产卵场研究, 推进江湖连通等水利调控措施与产卵场生态修复工程; (4) 渔业管理机制改革: 渔业 管理部门的工作重心应从渔业资源捕捞转向鱼类群落结构调整与生物多样性保护, 同时加强与环保、水利、 科研等相关单位的协同合作, 完成由传统的渔业管理向基于生态系统的管理模式的转变, 以实现洪泽湖渔 业的有序管理和可持续发展.

致谢: 在野外调查中得到了江苏省洪泽湖渔业管理委员会办公室与杨正金等渔民的帮助,在此谨致谢忱!

\section{4 参考文献}

[ 1 ] Wang SM, Dou HS eds. Chinese limnology record. Beijing: Science Press, 1998: 268-279. [王苏民, 窦鸿身. 中国湖泊 志. 北京: 科学出版社, 1998: 268-279.]

[ 2 ] Fan YM, He HC, Cui YX et al. Dynamic analysis of water area in the lake of Hongze basin. Resources and Environment in the Yangtze Basin, 2010, 19(12) : 1397-1403. [范亚民, 何华春, 崔云霞等. 淮河中下游洪泽湖水域动态变化研究. 长江流域资源与环境, 2010, 19(12)：1397-1403.]

[ 3 ] Sun J, Tang DY, Ji BC et al eds. Fisheries history of Hongze Lake. Nanjing: Jiangsu Publishing House of Science and Technology, 1990: 9-47. [孙坚, 汤道言, 季步成等. 洪泽湖渔业史. 南京: 江苏科学技术出版社, 1990: 9-47.] 
[ 4 ] Li B, Pu PM. Study on the evolution tendency of water quality in Huai river basin and Hongze Lake. Resources and Environment in the Yangtze Basin, 2003, 12(1)：67-73. [李波, 濮培民. 淮河流域及洪泽湖水质的演变趋势分析. 长江 流域资源与环境, 2003, 12(1): 67-73.]

[ 5 ] Wu XB. Change of Hongze Lake over 60 years. China Water Resources, 2009, 14: 21-23. [吴晓兵. 洪泽湖 60 年的变迁. 中国水利, 2009, 14: 21-23.]

[6] Zhu SQ, Dou HS eds. The Hongze Lake-Water resources and hydrobiology. Hefei: University of Science and Technology of China, 1993: 1-227. [ 朱松泉, 窦鸿身. 洪泽湖水资源和水生生物资源. 合肥: 中国科技大学出版社, 1993: 1-227.]

[ 7 ] Liu G, Li YM, Lv H et al. Remote sensing of chlorophyll-a concentrations in Lake Hongze using long time series MERIS observations. Chinese Journal of Environmental Science, 2017, 38(9) : 3645-3656. DOI: 10.13227/j. hjkx. 201702192. [刘阁, 李云梅, 吕恒等. 基于 MERIS 影像的洪泽湖叶绿素 a 浓度时空变化规律分析. 环境科学, 2017, 38(9): 3645-3656. ]

[ 8 ] Zhang CW, Zhang TL, Zhu TB et al. Community structure of macrozoobenthos and its relationship with environmental factors in Lake Hongze. Journal of Hydroecology, 2012, 33(3) : 27-33. DOI: 10.15928/j.1674-3075.2012.03.003. [张超 文, 张堂林, 朱挺兵等. 洪泽湖大型底栖动物群落结构及其与环境因子的关系. 水生态学杂志, 2012, 33(3): 27-33.]

[ 9 ] Zhao LS, Cheng F, Zhang L et al. Growth, mortality and evaluation of resource utilization for two Salangidae, Protosalanx hyalocranius and Neosalanx taihuensis in Hongze Lake. Acta Hydrobiologica Sinica, 2018, 42(2) : 240-249. DOI: 10. $7541 / 2018.030$. [ 赵丽爽, 程飞, 张否等. 洪泽湖大银鱼和太湖新银鱼的生长、死亡参数及资源利用状况. 水生生 物学报, 2018, 42(2): 240-249.]

[10] Lin ML, Zhang TL, Ye SW et al. Status of fish resources, historical variation and fisheries management strategies in Hongze Lake. Acta Hydrobiologica Sinica, 2013, 37(6): 1118-1127. DOI: 10.7541/2013.152. [林明利, 张堂林, 叶少文 等. 洪泽湖鱼类资源现状、历史变动和渔业管理策略. 水生生物学报, 2013, 37(6): 1118-1127.]

[11] Ni Y, Wu HL eds. Fishes of Jiangsu Province. Beijing: China Agriculture Press, 2006: 1-963. [倪勇, 伍汉霖. 江苏鱼 类志. 北京: 中国农业出版社, 2006: 1-963.]

[12] Pinkas L, Oliphant MS, Iverson ILK. Food habits of albacore, bluefin tuna, and bonito in California waters. California Department of Fish and Game Fish Bulletin, 1971, 152: 1-105.

[13] Krebs CJ ed. Ecological methodology. New York: Harper Collins Publishers, 1989: 328-368.

[14] Yi BL ed. Fish ecology. Wuhan: Huazhong Agricultural College Press, 1982: 2-4. [易伯鲁. 鱼类生态学. 武汉: 华中农 学院出版社, 1982: 2-4.]

[15] Charles HC. Design of fishways and other fish facilities. Boca Raton: CRC Press, 2017: 1-256.

[16] Liu WL, Deng W, Wang GX et al. Aquatic macrophyte status and variation characteristics in the past 50 years in Hongzehu Lake. Journal of Hydroecology, 2009, 2(6) : 1-8. DOI: 10.15928/j.1674-3075.2009.06.001. [刘伟龙, 邓伟, 王根 绪等. 洪泽湖水生植被现状及过去 50 多年的变化特征研究. 水生态学杂志, 2009, 2(6) : 1-8.]

[17] Mooney HA, Cleland EE. The evolutionary impact of invasive species. PNAS, 2001, 98 ( 10) : 5446-5451. DOI: 10. 1073/pnas.091093398.

[18] Mao ZG, Gu XH, Zeng QF et al. Community structure and diversity of fish in Lake Taihu. Chinese Journal of Ecology, 2011,30 (12) : 2836-2842. [毛志刚, 谷孝鸿, 曾庆飞等. 太湖鱼类群落结构及多样性研究. 生态学杂志, 2011,30 (12) : 2836-2842.]

[19] Magurran AE. Ecological diversity and its measurement. New Jersey: Princeton University Press, 1988: 7-45.

[20] Liu QG, Shen JZ, Chen MK et al. Advances of the study on the miniaturization of natural economical fish resources. Journal of Shanghai Fisheries University, 2005, 14(1): 79-83. [刘其根, 沈建忠, 陈马康等. 天然经济鱼类小型化问题 的研究进展. 上海水产大学学报, 2005, 14(1): 79-83.]

[21] Mao ZG, Gu XH, Zeng QF. The structure of fish community and changes of fishery resources in Lake Hulun. J Lake Sci, 2016, 28(2) : 387-394. DOI: 10.18307/2016.0219. [毛志刚, 谷孝鸿, 曾庆飞. 呼伦湖鱼类群落结构及其渔业资源 变化. 湖泊科学, 2016, 28(2): 387-394.]

[22] Chen P, Ma YW, Xie CG et al. Preliminary study on community structure of fishes in Bositeng Lake. Freshwater Fisheries, 2014, 44(2) : 36-42. [陈朋, 马燕武, 谢春刚等. 博斯腾湖鱼类群落结构的初步研究. 淡水渔业, 2014, 44(2): 
36-42.]

[23] Wilhm JL. Use of biomass units in Shannon's formula. Ecology, 1968, 49: 153-156. DOI: 10.2307/1933573.

[24] Olin M, Malinen T, Ruuhijärvi J. Gillnet catch in estimating the density and structure of fish community-Comparison of gillnet and trawl samples in a eutrophic lake. Fisheries Research, 2009, 96: 88-94. DOI: 10.1016/j.fishres.2008.09.007.

[25] Gibson-Reinemer DK, Ickes BS, Chick JH. Development and assessment of a new method for combining catch per unit effort data from different fish sampling gears: multigear mean standardization (MGMS). Canadian Journal of Fisheries and Aquatic Sciences, 2017, 74(1) : 8-14. DOI: 10.1139/cjfas-2016-0003.

[26] Pauly D, Christensen V, Dalsgaard J et al. Fishing down marine food webs. Science, 1998, 279(6) : 860-863. DOI: 10. 1126/science.279.5352.860.

[27] Li J, Wen ZR, Li GC et al. Relationship between crustacean zooplankton community structure and aquatic environmental factors of Meiliang and Gonghu Bay in Lake Taihu. Resources and Environment in the Yangtze Basin, 2014, 23(1) : 81-90. DOI : 10.11870/cjlyzyyhj2014Z1012. [李娟, 温周瑞, 李庚辰等. 太湖梅梁湾和贡湖湾浮游甲壳动物群落结构及其 与环境因子的相互关系. 长江流域资源与环境, 2014, 23(1): 81-90.]

[28] Fischer P, Öhl U. Effects of water-level fluctuations on the littoral benthic fish community in lakes: A mesocosm experiment. Behavioral Ecology, 2005, 16(4) : 741-746. DOI: 10.1093/beheco/ari047. 